Full-length article

\title{
Ginsenoside Rg1 reduces MPTP-induced substantia nigra neuron loss by suppressing oxidative stress ${ }^{1}$
}

\author{
Xiao-chun $\mathrm{CHEN}^{2}$, Yi-can ZHOU, Ying CHEN, Yuan-gui ZHU, Fang FANG, Li-min CHEN \\ Fujian Institute of Geriatrics, Union Hospital, Fujian Medical University, Fuzhou 350001, China
}

\section{Key words}

ginsenoside Rg1; $\mathrm{N}$-acetylcystein; apoptosis; JNK mitogen-activated protein kinases; inbred C57BL mice

\footnotetext{
${ }^{1}$ Project supported by Major Funding from the Fujian Department of Education (JA02219) and Key Grant from the Fujian Science and Technology Bureau (2001Z037).

${ }^{2}$ Correspondence to Prof. Xiao-chun CHEN. Phn 86-591-337-7664.

Fax 86-591-337-0393.

E-mail chenxc998@sohu.com
}

Received 2004-05-25

Accepted 2004-08-31

doi: 10.1111/j.1745-7254.2005.00019.x

\begin{abstract}
Aim: To investigate the effect of ginsenoside $\mathrm{Rg} 1$, an effective ingredient from ginsenoside, on 1-methyl-4-phenyl-1,2,3,6-tetrahydropyridine (MPTP)-induced substantia nigra neuron lesion. Methods: C57-BL mice were given MPTP to prepare Parkinson disease mice model. Different doses of $\operatorname{Rg} 1$ (5, 10, and 20 $\left.\mathrm{mg} \cdot \mathrm{kg}^{-1} \cdot \mathrm{d}^{-1}\right)$ or $N$-acetylcystein (NAC) $\left(300 \mathrm{mg} \cdot \mathrm{kg}^{-1} \cdot \mathrm{d}^{-1}\right)$ were given $3 \mathrm{~d}$ prior to MPTP in the pretreatment groups. Glutathione (GSH) level and total superoxide dismutase (T-SOD) activity in substantia nigra were determined by spectrophotometry. Nissl staining, tyrosine hydroxylase immunostaining, and TUNEL labeling were used to observe the damage and apoptosis of nigral neurons. Western blot analysis was used to detect the phospho-JNK and phospho-c-Jun levels in midbrain homogenates. Results: Pretreatments of C57-BL mice with different doses of Rg1 or NAC were found to protect against MPTP-induced substantia nigra neurons loss. Rg1 or NAC prevented GSH reduction and T-SOD activation in substantia nigra, and attenuated the phosphorylations of JNK and c-Jun following MPTP treatment. Conclusion: The antioxidant property of Rg1 along with the blocking of JNK signaling cascade might contribute to the neuroprotective effect of ginsenoside $\mathrm{Rg} 1$ against MPTP.
\end{abstract}

\section{Introduction}

The pathological hallmark of Parkinson disease (PD) is the loss of dopaminergic neurons in the substantia nigra (SN), which leads to the major clinical and pharmacological abnormalities that characterize the disease. Although the exact cause of neuronal loss is still unknown, current evidence points to the presence of ongoing oxidative stress and the generation of radical oxygen species (ROS) selectively in the pars compacta of substantia nigra (SNPC) of parkinsonian brain $\mathbf{s}^{[1,2]}$. Human postmortem studies also suggested that oxidative damage to lipids, proteins, and DNA occurred in the SNPC of PD patients ${ }^{[3-5]}$. The neurotoxin 1-methyl-4phenyl-1,2,3,6-tetrahydropyridine (MPTP) is metabolized in the brain by monoamine oxidase-B to its toxic metabolite, 1-methyl-4-phenylpyridinium ion $\left(\mathrm{MPP}^{+}\right)$, which is then selectively taken up into the dopaminergic neurons. $\mathrm{MPP}^{+}$ exerts its toxic effect in the dopaminergic neurons by inhib- iting mitochondrial NADH dehydrogenase (NADH-DH) ${ }^{[6]}$. MPTP could induce PD-like symptoms in humans and primates and causes degeneration of dopaminergic neurons in several animal species. The MPTP animal model is the ideal PD model for studying the pathogenesis of the disease.

The c-Jun $\mathrm{NH}_{2}$-terminal kinase (JNK) signaling cascade has been implicated as a mediator of MPTP-induced apoptotic neuronal death ${ }^{[7,8]}$. Oxidative stress is an important activator of the JNK signaling cascade. In differentiated $\mathrm{PC} 12$ cells and cultured sympathetic neurons, increases in oxidative stress induced by antisense inactivation of superoxide dismutase led to increased JNK activity ${ }^{[9]}$.

Current treatments of PD are symptomatic and lack neuroprotective effect. Antioxidants have been focused on as candidates for the future treatment of PD. Ginsenoside $\mathrm{Rg} 1$, one of the active ingredients of ginseng, has potential neurotrophic and neuroprotective effects ${ }^{[10]}$. In our previous study, we found Rg1 could protect substantia nigra neu- 
rons against MPTP-induced apoptosis ${ }^{[11]}$, and in a in vitro study we revealed that $\mathrm{Rg} 1$ could suppress intracellular oxidative stress to prevent PC12 cells from dopamine-induced apoptosis $^{[12]}$. The aim of the current study is to further investigate whether Rg1 could suppress oxidative stress and block the activation of the JNK signaling cascade, and therefore protects dopaminergic neurons from apoptosis in an MPTP animal model. One antioxidant $N$-acetylcystein, which has been proved to protect against MPTP-induced substantia nigra neurons $\operatorname{loss}^{[13]}$, was used as a positive contrast in this study.

\section{Materials and methods}

Animals and treatment Male C57-BL mice weighing 18-22 g were divided into six groups $(n=8)$. MPTP (Sigma, St Louis, MO, USA) was dissolved in saline at concentrations of $4 \mathrm{~g} / \mathrm{L}$. Ginsenoside $\operatorname{Rg} 1$ (purity $>98 \%$ ), obtained from the Department of Organic Chemistry of Norman Bethune Medical University (Changchun, Jilin, China), was also dissolved in saline at concentrations of $1 \mathrm{~g} / \mathrm{L}$. Model animals were injected subcutaneously with saline for $3 \mathrm{~d}$, followed by injection (subcutaneously) of MPTP (30 $\mathrm{mg} \cdot \mathrm{kg}^{-1} \cdot \mathrm{d}^{-1}$ ) for 5 consecutive days. Three preventive groups were injected (ip) with $\mathrm{Rg} 1\left(5 \mathrm{mg} \cdot \mathrm{kg}^{-1} \cdot \mathrm{d}^{-1}, 10 \mathrm{mg} \cdot \mathrm{kg}^{-1} \cdot \mathrm{d}^{-1}, 20\right.$ $\left.\mathrm{mg} \cdot \mathrm{kg}^{-1} \cdot \mathrm{d}^{-1}\right)$. Positive contrast group was injected (sc) with NAC (Jingke, Beijing, China, $300.0 \mathrm{mg} \cdot \mathrm{kg}^{-1} \cdot \mathrm{d}^{-1}$ ) for 8 days, and from the fourth day both $\mathrm{Rg} 1$ preventive groups and the positive contrast group were received injection (sc) of MPTP (30 $\mathrm{mg} \cdot \mathrm{kg}^{-1} \cdot \mathrm{d}^{-1}, 2 \mathrm{~h}$ after $\mathrm{Rg} 1$ or NAC injection) for $5 \mathrm{con}$ secutive days. The control group received saline only. The animals were killed $24 \mathrm{~h}$ after the last injection. The mice were anaesthetized with euthanal and perfused transcardially with ice-cold saline prior to decapitation. The midbrain containing the substantia nigra was dissected, and quickly frozen at $-80^{\circ} \mathrm{C}$ until ready for later analysis. For immunohistochemistry analysis, the midbrain was fixated in $4 \%$ formal-dehydum polymerisatum-PB and imbedded in paraffin. Serial 5- $\mu$ m-thick sections were cut transversely from the middle of the midbrain.

Spectrophotometry Substantia nigra were homogenized with $0.01 \mathrm{~mol} / \mathrm{L}$ Tris- $\mathrm{HCl}$ ( $\mathrm{pH} 7.4$ ) consisting of $0.01 \mathrm{~mol} / \mathrm{L}$ sucrose and $0.1 \mathrm{mmol} / \mathrm{L}$ EDTA, followed by centrifugation at $4000 \times g$ for $15 \mathrm{~min}$. The supernatant was saved and analyzed. The dithio-binitrobenzoic acid method and xanthine/xanthine oxidase method were used to test glutathione (GSH) level and total superoxide dismutase (T-SOD) activity. Reaction product was determined by spectrophotometry. Test Kits were purchased from Jian Cheng Bioengineering Insti- tute (Nanjing, China).

TUNEL Deparaffinized and hydrated sections were incubated with proteinase $\mathrm{K}(20 \mathrm{mg} / \mathrm{L}$ in $10 \mathrm{mmol} / \mathrm{L}$ Tris/ $\mathrm{HCl}, \mathrm{pH}=7.4-8.0$ ) for $30 \mathrm{~min}$ at $37^{\circ} \mathrm{C}$, then incubated with $\mathrm{TdT}$ reaction mixture and AP-conjugated anti-fluorescein antibody (TUNEL detection kit, BM, Germany) for $1 \mathrm{~h}$ at $37^{\circ} \mathrm{C}$. Finally sections were visualized with NBT-BCIP. The nuclei of positive cells were stained blue-black.

Nissl staining Paraffin sections were deparaffinized and hydrated, stained with methylene blue buffer for $10 \mathrm{~min}$ and then immersed into acetic acid buffer for $2 \mathrm{~min}$.

Immunohistochemistry Paraffin sections were deparaffinized and hydrated, then incubated with a goat antimouse TH polyclonal antibody (1:40 dilution in $0.01 \mathrm{mmol} / \mathrm{L}$ phosphate buffer saline, $\mathrm{pH} 7.4$ ) at $4{ }^{\circ} \mathrm{C}$ overnight. Slides were then incubated with a biotinylated rabbit anti-goat $\mathrm{IgG}$ and SABC-reagent (SABC kit, BOSTER, Wuhan, Hubei, China), respectively for $30 \mathrm{~min}$ at $37^{\circ} \mathrm{C}$. At last, sections were stained with diaminobenzidine (DAB). Hemotoxylin was used to counterstain nuclei for one minute.

Western blot analysis Substantia nigra was homogenized $(50 \mathrm{~g} / \mathrm{L})$ in lysis buffer $(10 \mathrm{mmol} / \mathrm{L}$ Tris, $50 \mathrm{mmol} / \mathrm{L}$ $\mathrm{NaCl}, 0.03 \mu \mathrm{mol} / \mathrm{L}$ sodium pyrophosphate, $50 \mathrm{mmol} / \mathrm{L}$ sodium fluoride, and $1 \%$ Triton X-100) containing $1 \mathrm{mmol} / \mathrm{L}$ phenylmethylsulfonyl fluoride, $20 \mathrm{mg} / \mathrm{L}$ aprotinin, and 1 $\mathrm{mmol} / \mathrm{L}$ sodium vanadate ${ }^{[14]}$. After homogenization, samples were centrifuged at $15000 \times g$ for $15 \mathrm{~min}$. The supernatants were taken for further analysis. Protein concentration was determined by the Bradford method ${ }^{[15]}$. Approxiamately 10 $\mu \mathrm{g}$ of total protein was separated by $12 \%$ sodium dodecyl sulfate-polyacrylamide gel electrophoresis (SDS-PAGE) and transferred to nitrocellulose membranes. The membranes were probed with polyclonal anti-p-JNK1/2 or anti-p-c-Jun rabbit antibody (Cell Signaling, Beverly, MA, USA). Immunoreactive bands were visualized by the addition of horseradish peroxidase-conjugated antibodies against rabbit Fab and chemiluminescent substrates (Pierce, Rockford, IL, USA), according to the manufacturer's instruction.

Image analysis The numbers of Nissl, TH, TUNELpositive neurons in full microscopic fields of SN were counted with a digital medical image analysis system (Motic, Beijing, China). Three tissue sections per animal were counted for each index.

Data analysis Data were expressed as means \pm SEM. TUNEL-positive cells were calculated as: [TUNEL-positive cells/(TUNEL-positive cells+Nissl staining cells)] $\times 100 \%$. For statistical evaluation one-way analysis of variance (ANOVA) was employed. Student Newman Keuls test was performed when variance was equal, and Games-Howell test 
was performed when variance was not equal. Pearson correlation analysis was also carried out to some indices. Statistical difference was considered to be significant only if $P$ $<0.05$.

\section{Results}

Effect of ginsenoside Rg1 on MPTP-induced apoptosis of substantia nigra neurons MPTP clearly had a detrimental effect on dopaminergic neurons. Treatment with MPTP decreased the numbers of TH-positive and Nisslpositive neurons and increased the percent of TUNELpositive neurons in SN. Pretreatment with ginsenoside Rg1 or NAC significantly ameliorated the neuronal loss and apoptosis induced by MPTP $(P<0.01)$ (Figure 1-3). $\mathrm{Rg} 1$ at $10 \mathrm{mg} / \mathrm{kg}$ showed the best protective effect among all the doses but made no significant difference $(P>$ 0.05 ) at $5 \mathrm{mg} / \mathrm{kg}$ and $20 \mathrm{mg} / \mathrm{kg}$, which suggested that the effect of ginsenoside $\mathrm{Rg} 1$ might have an optimal dose range. There was no significant difference between NAC and $\mathrm{Rg} 1(10 \mathrm{mg} / \mathrm{kg})$ treatment group.

Effect of ginsenoside Rg1 on GSH level and T-SOD activity in SN Decreased GSH level and increased T-SOD activity were detected in the substantia nigra of MPTP-treated mice. Both changes were attenuated by pre-administration with ginsenoside Rg1 or NAC (Table $1, P<0.01$ ). Better preventive effects were observed at doses of 10 and 20 $\mathrm{mg} / \mathrm{kg}$ than at $5 \mathrm{mg} / \mathrm{kg}$ among $\mathrm{Rg} 1$ treated groups, but there was no significant difference among $10 \mathrm{mg} / \mathrm{kg}, 20 \mathrm{mg} / \mathrm{kg}$ of $\mathrm{Rg} 1$, and NAC $(300.0 \mathrm{mg} / \mathrm{kg})$. Correlation analysis showed a positive correlation between the positive neuron ratio of $\mathrm{TH}$ and the GSH level $(r=0.885, P<0.01)$, and negative correlation between the positive neuron ratio of TH and the TSOD activity $(r=-0.882, P<0.01)$. These results indicate that

Table 1. Effect of ginsenoside Rg1 on GSH level and T-SOD activity. Mean \pm SEM. $n=8 .{ }^{\mathrm{c}} P<0.01$ vs control group. ${ }^{\mathrm{f}} P<0.01$ vs MPTP group. ${ }^{\text {i }} P<0.01$ vs MPTP $+\mathrm{Rg} 15 \mathrm{mg} / \mathrm{kg}$ group.

\begin{tabular}{lll}
\hline Group & $\begin{array}{c}\text { GSH level/ } \\
\mathrm{mg} \cdot \mathrm{mg}^{-1} \text { protein }\end{array}$ & $\begin{array}{c}\text { SOD activity/ } \\
\mathrm{NU} \cdot \mathrm{mg}^{-1} \text { protein }\end{array}$ \\
\hline MPTP & $35.30 \pm 0.81^{\mathrm{c}}$ & $142.42 \pm 1.0^{\mathrm{c}}$ \\
Control & $56.96 \pm 0.41$ & $116.53 \pm 1.03$ \\
MPTP+NAC(300 mg/kg $)$ & $56.18 \pm 0.74^{\mathrm{fc}}$ & $118.38 \pm 0.85^{\mathrm{fi}}$ \\
MPTP+Rg1 $(5 \mathrm{mg} / \mathrm{kg})$ & $40.36 \pm 0.53^{\mathrm{f}}$ & $131.85 \pm 0.79^{\mathrm{f}}$ \\
MPTP+Rg1 $(10 \mathrm{mg} / \mathrm{kg})$ & $50.09 \pm 0.48^{\mathrm{fi}}$ & $120.90 \pm 0.89^{\mathrm{fi}}$ \\
MPTP+Rg1 $(20 \mathrm{mg} / \mathrm{kg})$ & $50.44 \pm 0.36^{\mathrm{fi}}$ & $122.84 \pm 0.73^{\mathrm{fi}}$ \\
\hline
\end{tabular}

enhanced oxidative stress was involved in the neurotoxicity of MPTP; and suitable doses of Rg1 could attenuate the oxidative stress induced by MPTP, while overdoses of Rg1 did not show better preventive effect.

Influence of MPTP-induced JNK and c-Jun phosphorylation by ginsenoside Rg1 MPTP treatment increased the levels of p46 and p54 phospho-JNK protein, as compared with the control. Preadministration of Rg1 or NAC partially attenuated the MPTP-mediated elevation in phospho-JNK and phospho-c-Jun levels in midbrain homogenates. A $10 \mathrm{mg} / \mathrm{kg}$ dose of $\mathrm{Rg} 1$ showed the greatest inhibition as did NAC, but the weak inhibition was observed at the dose of $20 \mathrm{mg} / \mathrm{kg}$. These results suggested that $\mathrm{Rg} 1$ attenuated MPTP-induced phosphorylation of JNK and c-Jun, but a higher dosage was detrimental.

\section{Discussion}

Ginseng has been used in traditional Chinese medicine to enhance stamina and capacity to deal with fatigue and physical stress for thousands of years. Ginsenoside Rg1 is one of the active ingredients of ginseng. Previous in vitro studies showed that $\operatorname{Rg} 1$ could save cell from oxidative stress induced-apoptosis ${ }^{[16]}$. In the current study, we observed that TH-positive neurons loss in SN caused by MPTP could be attenuated by $\operatorname{Rg} 1$ or NAC pretreatment; the result showed the neuronal protective effect of ginsenoside $\operatorname{Rg} 1$ against MPTP. Our study also revealed the neuroprotective mechanisms of Rg1 in preventing MPTP-induced loss of dopaminergic neurons in SN. The neurotoxin of MPTP is dependent on the inhibition of Complex I in the mitochondrial respiratory chain by $\mathrm{MPP}^{+}$, subsequently followed by ATP depletion and increased production of $\operatorname{ROS}^{[17]}$, eventually leads to the cell death. As one of the most important antioxidant molecule, $\mathrm{GSH}$ could clear $\mathrm{H}_{2} \mathrm{O}_{2}$ and prevent its reaction with iron to form the highly reactive $\mathrm{OH}^{-}$radical in the Fenton reaction. Following MPTP treatment, GSH was consumed and its level dropped ${ }^{[18,19]}$. We also observed the activity of T-SOD (including $\mathrm{Cu} / \mathrm{Zn}-\mathrm{SOD}$ and Mn-SOD), another important radical scavenger, was elevated in SN of MPTP treated mice; this change corresponded with those observed in PD patients ${ }^{[20-22]}$. NAC is a free radical oxygen scavenger. Furthermore, it can be converted into cysteine after entering cells, and is an important substrate for GSH production. In our current study, pretreatment with NAC could attenuate the loss of GSH and the increased activity of T-SOD following MPTP treatment, same changes were observed among Rg1 pretreatment groups. We found that the antioxidative effect of $\mathrm{Rg} 1$ had an optimal dose of $10 \mathrm{mg} / \mathrm{kg}$, this dosage 

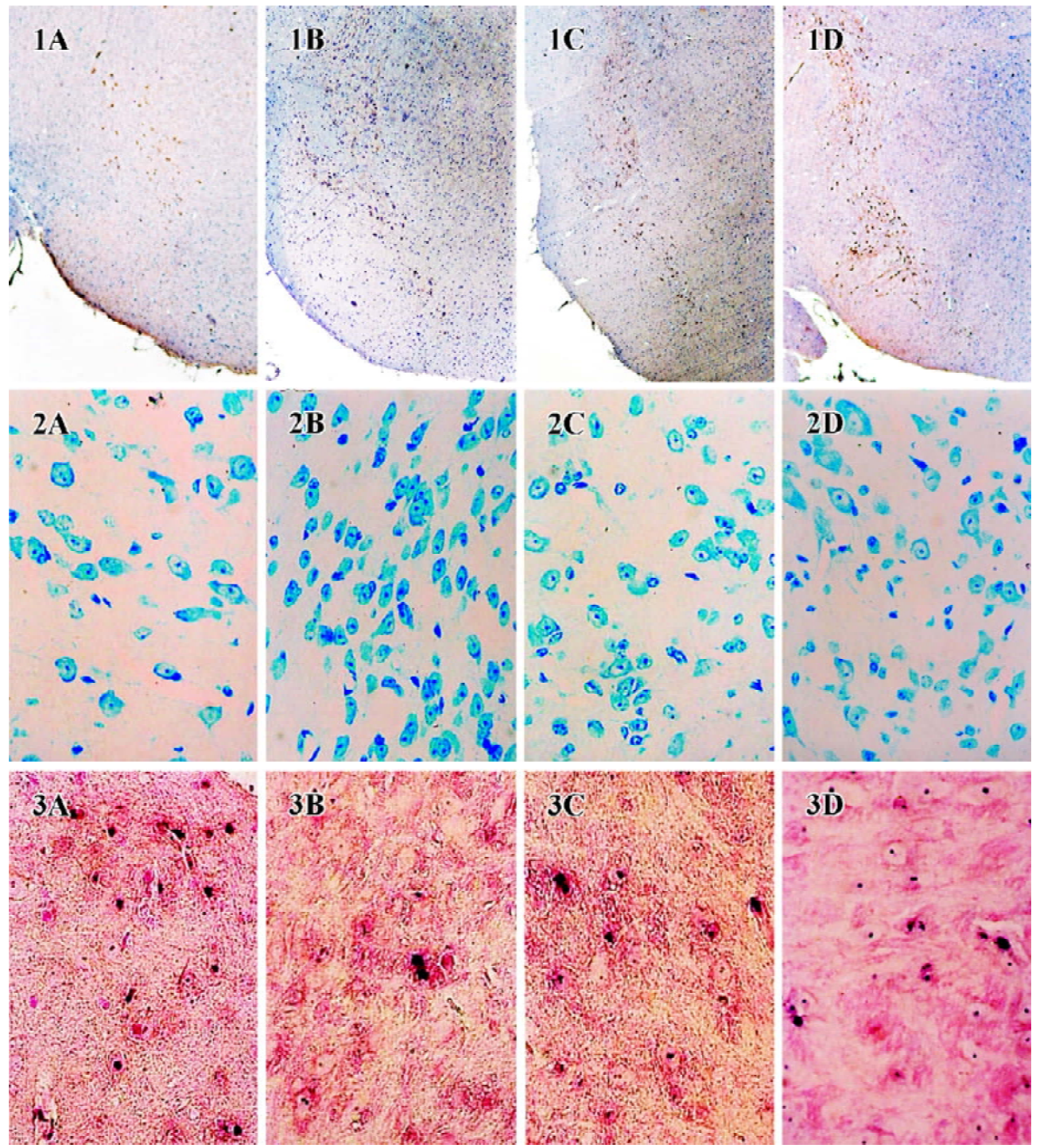

Figure 1. TH immunostaining (1), Nissl staining (2), and TUNEL staining (3) of mouse substantia nigra neurons. A: model group; B: control group; C: pretreatment with NAC group at $300.0 \mathrm{mg} / \mathrm{kg}$; D: pretreatment with $\mathrm{Rg} 1$ group at $10.0 \mathrm{mg} / \mathrm{kg} ; 1: \times 40.2,3: \times 400$.

of Rg1 showed the similar effect as NAC, but there was no improvement beyond this dose. The results demonstrated that $\operatorname{Rg} 1$ possessed the same antioxidant property as NAC.

There has been no direct evidence indicating that $\mathrm{Rg} 1$ could scavenge radical by itself, therefore we tried to investigate whether Rg1 act as an antioxidant through mediator. In our previous study, we found the protective effect of $\mathrm{Rg} 1$ against MPTP-induced nigral neurons apoptosis was related to enhancing Bcl-2 expression and reducing iNOS expres$\operatorname{sion}^{[11]}$. Bcl-2 is an anti-apoptotic protein located in the outer mitochondrial membrane, nuclear membrane and endoplasmic reticulum membrane. Bcl-2 participates in the regulation of cell death through multiple mechanisms, one of which regulates the steady state of cellular ROS levels. This can be achieved either by modulating their production, usually by the mitochondria, or by affecting the antioxidant capacity of the cells. In vitro and in vivo studies provided evidences that Bcl-2 could attenuate cell injuries caused by oxidative stress. Bcl-2 could protect against the increased level of ROS caused by dopamine metabolism in PC12 cells $^{[23]}$. Transfection with Bcl-2 provided the PC12 cells with marked protection against dopamine-induced apoptosis and inhibited dopamine oxidation to dopamine-melanin ${ }^{[24]}$. Further studies demonstrated enhanced oxidative stress and susceptibility to oxidants in the brains of Bcl-2-deficient mice $^{[25]}$. Our previous study showed that $\operatorname{Rg} 1$ could prevent 


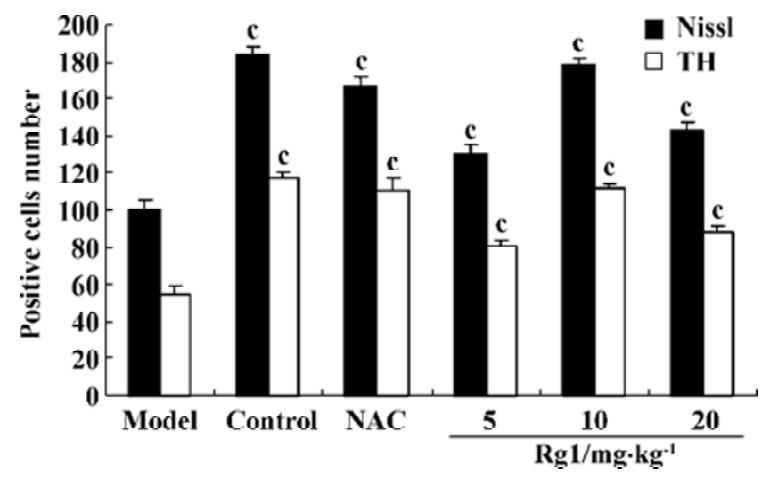

Figure 2. Number of Nissl (black) and TH (white) staining-positive neurons in SN. Pretreatment with Rg1 significantly increased the number of survival neurons and TH-positive neurons, as determined by one-way ANOVA. A $10 \mathrm{mg} / \mathrm{kg}$ dose of $\mathrm{Rg} 1$ showed the best protective effect among all the doses, and showed no significant difference with NAC. $n=8$. Mean \pm SEM. ${ }^{\mathrm{c}} P<0.01$ vs the model group.

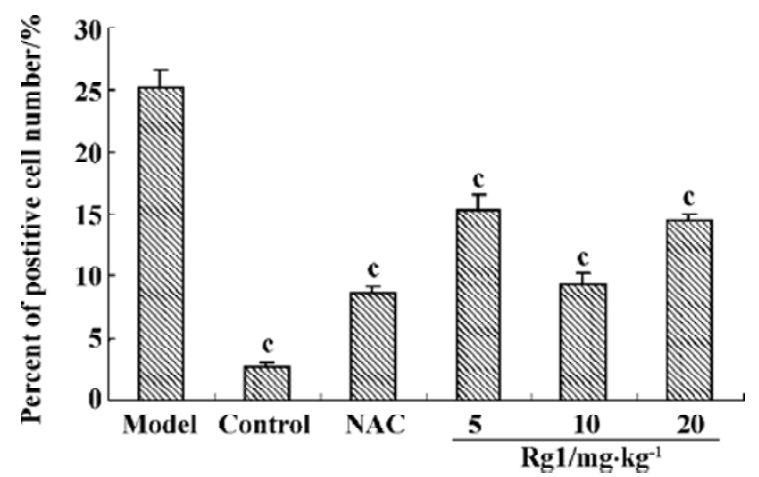

Figure 3. Percentage of TUNEL-positive neuron numbers in SN. The percentage of TUNEL-positive neurons in the model group increased significantly compared with other groups. Pretreatment with Rg1 significantly decreased the percentage of TUNEL-positive neurons. A $10 \mathrm{mg} / \mathrm{kg}$ dose of Rg1 showed the best preventive effect of all the doses, and showed no significant difference with NAC. $n=8$. Mean \pm SEM. ${ }^{\mathrm{c}} P<0.01$ vs the model group.
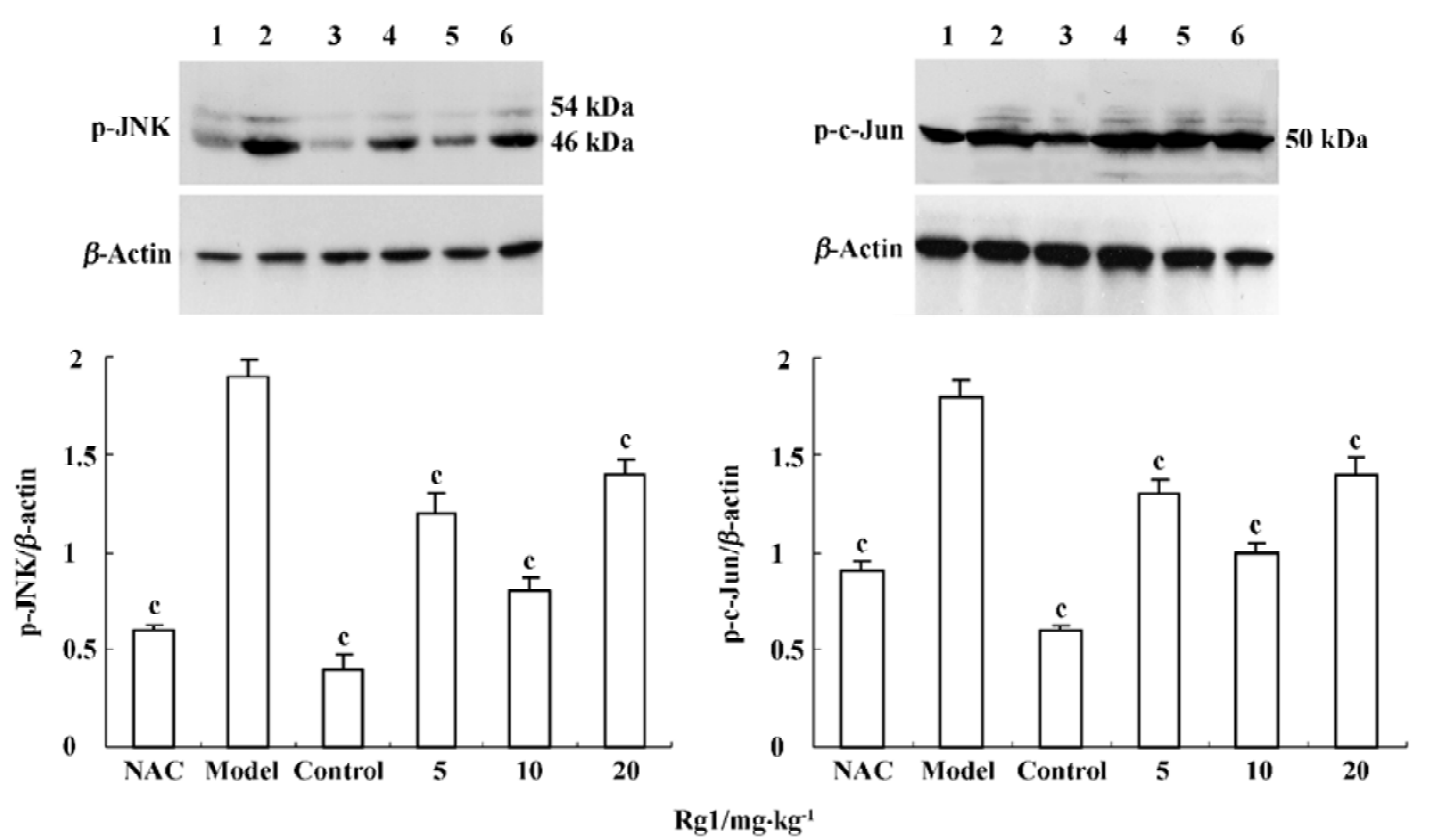

Figure 4. Western blot detection of phospho-JNK and phospho-c-Jun levels respectively. The histogram showed the comparisons of $O D$ odds among different groups. 1: NAC; 2: model; 3: control; 4: $5 \mathrm{mg} / \mathrm{kg} \mathrm{Rg1+MPTP;} \mathrm{5:} 10 \mathrm{mg} / \mathrm{kg} \mathrm{Rg} 1+\mathrm{MPTP} ; 6: 20 \mathrm{mg} / \mathrm{kg} \mathrm{Rg} 1+\mathrm{MPTP} . \quad n=3$. Mean \pm SEM. ${ }^{\mathrm{c}} P<0.01 v s$ the MPTP group.

the decrease of Bcl-2-positive cell numbers following MPTP treatment, so this might contribute to the antioxidant property of Rg1.

Another important protein involved in oxidative stress is nitric oxide synthase (NOS), of which three isoforms have been described: neuronal NOS (nNOS) and endothelial NOS are calcium-calmodulin-dependent enzymes, while inducible NOS (iNOS) activity is independent of intracellular calcium levels. Nitric oxide (NO), an important free radical generated by NOS, can react with superoxide radicals to form the oxidizing agents peroxynitrite $\left(\mathrm{ONOO}^{-}\right)$and $\mathrm{OH}^{-[26]}$, and eventually induce DNA strand breakage and apoptosis ${ }^{[27]}$. 
Numerous experimental studies have shown that iNOS play an important role in MPTP-induced dopaminergic neuron injury or in PD patients ${ }^{[28,29]}$, it is in agreement with our previous observation that MPTP increased the numbers of iNOSpositive cells. Therefore, changes of Bcl-2 and iNOS expressions could play important roles in the antioxidative effect of $\mathrm{Rg} 1$, this could explain the antioxidant property of $\mathrm{Rg} 1$. However, the exact pathway leading to the changes of Bcl-2 and iNOS expression in SN is still unclear.

The JNK signaling cascade is a main pathway that mediates the neurotoxicity of MPTP ${ }^{[14]}$, CEP-1347/KT-7515, an inhibitor of JNK activation, can attenuate MPTP-induced nigrostriatal dopaminergic degeneration ${ }^{[7]}$. Transgenic mice expressing the JNK binding domain (JBD) of JNK interacting protein 1 could resist the neurotoxicity of $\mathrm{MPTP}^{[8]}$. Oxidative stress is an important activator of the JNK signaling cascade. In differentiated PC12 cells and cultured sympathetic neurons, oxidative stress induced by antisence inactivation of superoxide dismutase increased JNK activity ${ }^{[9]}$. In our previous study, we observed that JNK pathway was activated after the exposure of SHSY5Y cells to the mitochondrial complex I inhibitor $\mathrm{MPP}^{+}, \mathrm{Rg} 1$ could attenuate the elevation of ROS and reduce the JNK activation after $\mathrm{MPP}^{+}$treatment ${ }^{[30]}$. In the present in vivo study, we also found that pretreatment with $\mathrm{Rg} 1$ or NAC could attenuate the elevated phosphorylation of JNK and c-Jun induced by MPTP in SN. The dose of $10 \mathrm{mg} / \mathrm{kg}$ of Rg1 showed better effect than dose of $5 \mathrm{mg} / \mathrm{kg}$ and $20 \mathrm{mg} / \mathrm{kg}$. There was no significant difference between NAC and $10 \mathrm{mg} / \mathrm{kg} \mathrm{Rg1,} \mathrm{but}$ it is a puzzle why $20 \mathrm{mg} / \mathrm{kg} \mathrm{Rg} 1$ had weaker inhibition than $10 \mathrm{mg} / \mathrm{kg} \mathrm{Rg}$. The toxicity of higher doses of $\mathrm{Rg} 1$ could compromise its ability as a radical scavenger. However, this change is associated with the loss of dopaminergic neurons at different $\mathrm{Rg} 1$ doses. This results confirms previous studies that JNK signaling cascade play an important role in dopaminergic neuron apoptosis induced by MPTP, and appropriate dose of $\mathrm{Rg} 1$ could attenuate the MTPT induced activation of JNK signaling cascade. It requires further study to find out whether Rg1 influences JNK pathway through mechanisms other than antioxidation.

In conclusion, the present study indicates that pretreatment with certain doses of $\mathrm{Rg} 1$ could reduce the loss of dopaminergic neurons caused by MPTP in SN. The neuroprotective effects of $\operatorname{Rg} 1$ are potentially due to its antioxidant property that involves Bcl-2 and iNOS, and its inhibitory effect on JNK signaling cascade activation. Further studies will be carried out to evaluate whether ginsenoside $\mathrm{Rg} 1$, an important ingredient of ginsenoside, could benefit as a future preventive and therapeutic drug of PD.

\section{References}

1 Gerlach M, Ben-Shachar D, Riederer P, Youdim MB. Altered brain metabolism of iron as a cause of neurodegenerative diseases? J Neurochem 1994; 63: 793-806.

2 Jenner P, Olanow CW. Pathological evidence for oxidative stress in Parkinson's disease and related degenerative disorders. In: Olanow $\mathrm{CW}$, Jenner P, Youdim MBH, editors. Neurodegeneration and neuroprotection in Parkinson's disease. London: Academic Press; 1996. p 24-45.

3 Alam ZI, Jenner A, Daniel SE, Lees AJ, Cairns N, Marsden CD, et al. Oxidative DNA damage in the parkinsonian brain: an apparent selective increase in 8-hydroxyguanine levels in substantia nigra. J Neurochem 1997; 69: 1195-203.

4 Dexter DT, Holley AE, Flitter WD, Slater TF, Wells FR, Daniel SE, et $a l$. Increased levels of lipid hydroperoxides in the parkinsonian substantia nigra: an HPLC and ESR study. Mov Disord 1994; 9: 92-7.

5 Zhang J, Perry G, Smith MA, Robertson D, Olson SJ, Graham DG, et al. Parkinson's disease is associated with oxidative damage to cytoplasmic DNA and RNA in substantia nigra neurons. Am J Pathol 1999; 154: 1423-9.

6 Ramsay RR, Salach JI, Dadgar J, Singer TP. Inhibition of mitochondrial NADH dehydrogenase by pyridine derivatives and its possible relation to experimental and idiopathic parkinsonism. Biochem Biophys Res Commun 1986; 135: 269-75.

7 Saporito MS, Brown EM, Miller MS, Carswell S. CEP-1347/KT7515 , an inhibitor of c-jun $\mathrm{N}$-terminal kinase activation, attenuates the 1-methyl-4-phenyl-tetrahydro-pyridine-mediated loss of nigrostriatal dopaminergic neurons in vivo. J Pharmacol Exp Ther 1999; 288: 421-7.

8 Xia XG, Harding T, Weller M, Bieneman A, Uney JB, Schulz JB. Gene transfer of the JNK interacting protein-1 protects dopaminergic neurons in the MPTP model of Parkinson's disease. Proc Natl Acad Sci USA 2001; 98: 10433-8.

9 Maroney AC, Finn JP, Bozyczko-Coyne D, O'Kane TM, Neff NT, Tolkovsky AM, et al. CEP-1347 (KT-7515), an inhibitor of JNK activation, rescues sympathetic neurons and neuronally differentiated PC12 cells from death evoked by three distinct insults. J Neurochem 1999; 73: 1901-12.

10 Rudakewich M, Ba F, Benishin CG. Neurotrophic and neuroprotective actions of ginsenoside $\operatorname{Rb}(1)$ and $\operatorname{Rg}(1)$. Planta Med 2001; 67: 533-7.

11 Chen XC, Chen Y, Zhu YG, Fang F, Chen LM. Protective effect of ginsenoside Rg1 on MPTP-induced apoptosis in mouse substantia nigra neurons and its mechanisms. Acta Pharmacol Sin 2002; 23: 829-34.

12 Chen XC, Zhu YG, Zhu LA, Huang C, Chen Y, Chen LM, et al. Ginsenoside Rg1 attenuates dopamine-induced apoptosis in $\mathrm{PC} 12$ cells by suppressing oxidative stress. Eur J Pharmacol 2003; 473: 1-7.

13 Perry TL, Yong VW, Clavier RM, Jones K, Wright JM, Foulks JG, et al. Partial protection from the dopaminergic neurotoxin $\mathrm{N}$-methyl-4phenyl-1,2,3,6 tetrahydropyridine by four different antioxidants in the mouse. Neurosci Lett 1985; 60: 109-14.

14 Saporito MS, Thomas BA, Scott RW. MPTP activates c-Jun $\mathrm{NH}_{2}$ terminal kinase (JNK) and its upstream regulatory kinase MKK4 in nigrostriatal neurons in vivo. J Neurochem 2000; 75: 1200-8.

15 Bradford MM. A rapid and sensitive for the quantitation of microgram quantitites of protein utilizing the principle of protein-dye binding. Anal Biochem 1976; 72: 248-54. 
16 Liao B, Newmark H, Zhou R. Neuroprotective effects of ginseng total saponins and ginsenosides Rb1 and Rg1 on spinal cord neurons in vitro. Exp Neurol 2002; 173: 224-34.

17 Ali SF, David SN, Newport GD, Cadet JL, Slikker W Jr. MPTPinduced oxidative stress and neurotoxicity are age-dependent: evidence from measures of reactive oxygen species and striatal dopamine levels. Synapse 1994; 18: 27-34.

18 Grunblatt E, Mandel S, Maor G, Youdim MBH. Effect of $R$ - and $S$ apomorphine on MPTP-induced nigro-striatal dopamine neuronal loss. J Neurochem 2001; 77: 146-56.

19 Sriram K, Pai KS, Boyd MR, Ravindranath V. Evidence for generation of oxidative stress in brain by MPTP: in vitro and in vivo studies in mice. Brain Res 1997; 749: 44-52.

20 Marttila RJ, Lorentz H, Rinne UK. Oxygen toxicity protecting enzymes in Parkinson's disease. Increase of superoxide dismutase-like activity in the substantia nigra and basal nucleus. J Neurol Sci 1988; 86: 321-31.

21 Saggu H, Cooksey J, Dexter D, Wells FR, Lees A, Jenner P, et al. A selective increase in particulate superoxide dismutase activity in Parkinsonian substantia nigra. J Neurochem 1989; 53: 692-7.

22 Yoritaka A, Hattori N, Mori H, Kato K, Mizuno Y. An immunohistochemical study on manganese superoxide dismutase in Parkinson's disease. J Neurol Sci 1997; 148: 181-6.

23 Ziv I, Offen D, Barzilai A, Haviv R, Stein R, Zilkha-Falb R, et al.
Modulation of control mechanism of dopamine-induced apoptosis-a future approach to the treatment of Parkinson's disease? J Neural Transm Suppl 1997; 49: 195.

24 Offen D, Ziv I, Panet H, Wasserman L, Stein R, Melamed E, et al. Dopamine-induced apoptosis is inhibited in PC12 cells expressing Bcl-2. Mol Cell Neurol 1997; 17: 289-304.

25 Hochman A, Sternin H, Gorodin S, Korsmeyer S, Ziv I, Melamed E, et al. Enhanced oxidative stress and altered antioxidants in brains of Bcl-2-deficient mice. J Neurochem 1998; 71: 741-8.

26 Beckman JS, Beckman TW, Chen J, Marshall PA, Freeman BA. Apparent hydroxyl radical production by peroxynitrite: implications for endothelial injury from nitrite oxide and superoxide. Proc Natl Acad Sci USA 1990; 87: 1620-4.

27 Lin KT, Xue JY, Nomen M, Spur B, Wong PY. Peroxynitrite-induced apoptosis in HL-60 cells. J Biol Chem 1995; 270: 16487-90.

28 Dehmer T, Lindenau J, Haid S, Dichgans J, Schulz JB. Deficiency of inducible nitric oxide synthase protects against MPTP toxicity in vivo. J Neurochem 2000; 74: 2213-6.

29 Hunot S, Boissiere F, Faucheux B, Brugg B, Mouatt-Prigent A, Agid $\mathrm{Y}$, et al. Nitrite oxide synthase and neuronal vulnerability in Parkinson's disease. Neuroscience 1996; 72: 355-63.

30 Chen XC, Fang F, Zhu YG, Chen LM, Zhou YC, Chen Y. Protective effect of ginsenoside $\mathrm{Rg} 1$ on $\mathrm{MPP}^{+}$-induced apoptosis in SHSY5Y cells. J Neural Transm 2003; 110: 835-45. 